\title{
Effects of combined application of organic and inorganic fertilizers on yield and quality of Chinese cabbage
}

\author{
Huan Liu ${ }^{1, a}$, Haiyan Wang ${ }^{2, b}$, Dan Yang ${ }^{3, \mathrm{c}}, \mathrm{Na} \mathrm{He}^{4, \mathrm{~d}}$ and Mingda Liu ${ }^{5, \mathrm{e}}$, \\ 1,2,3,4,5 College of Land and Environmental Science, Shenyang Agricultural University, Shenyang \\ 110866, P.R. China, \\ ao0913964004@163.com, ${ }^{\mathrm{b}} 13555826547 @ 163 . c o m,{ }^{\mathrm{c}} 165170874 @ q q . c o m$, \\ d513912817@qq.com, ${ }^{\mathrm{e}}$ corresponding author mdsausoil@163.com
}

\begin{abstract}
Keywords: combined application; organic fertilizers; inorganic fertilizers; Chinese cabbage; yield; quality.

Abstract. Effects of combined application of organic and inorganic fertilizers on yield and quality of Chinese cabbage were studied. The results showed that combined application of organic and inorganic fertilizers can improve the yield of Chinese cabbage, reduce the moisture content of plant, and improve the titratable acidity and the soluble sugar content. Compared with the chemical fertilizer treatment, effects of combined application of organic and inorganic fertilizers on nitrate content of Chinese cabbage were variable. In general, combined application of organic and inorganic fertilizer can improve the yield and quality of Chinese cabbage.
\end{abstract}

\section{Introduction}

Chinese cabbage is an important vegetable in China, especially in the north China where it is the main vegetable in the winter. With the development of society and economy, people have higher demands to requirements for the quality of vegetables. In the growth process of vegetable, a large number of chemical fertilizers were used, leading to heavy metal contamination in soil [1], soil harden [2], soil acidification [3], and imbalances of soil elements.

Chemical fertilizer are not only harmful to soil, but also have an adverse impact on crop. Applying chemical fertilizers to soil resulted in excessive accumulation of nitrate in plants[4]. Superfluous phosphorus fertilizer in soil can limit plant absorption of calcium, magnesium, potassium and trace elements such as manganese, copper, zinc and iron. Thus the plant quality reduced. At the same time, the excess of chemical fertilizer will cause harm to the environment. Chemical fertilizer into the water can cause eutrophication and nitrate pollution [5,6]. Chemical fertilizers application in soil result in $\mathrm{N}_{2} \mathrm{O}$ emissions, which is a by-product of the transformation of $\mathrm{N}$ compounds added to soil [7]. In certain conditions, nitrogen could be volatile, generating $\mathrm{NH}_{3}$ into the environment, and become one of the ingredients of acid rain and soil acidification [8].

Organic fertilizers can be used as a substitute for chemical fertilizers to eliminate the disadvantage. But using organic fertilizer alone cannot meet the needs of the plant and lead to lower yield. Combined application of organic and inorganic fertilizers was an effective way to find a balance between yield and quality. This study may help to improve the quality of Chinese cabbage by combined application of organic and inorganic fertilizers.

\section{Materials and Methods}

Description of the study site. The study was conducted at Shenyang hawthorn country field scientific

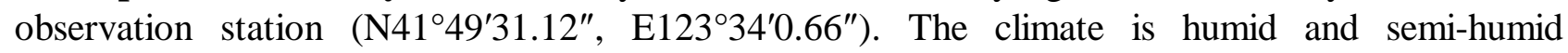
continental monsoon, with a local mean annual precipitation of $700 \mathrm{~mm}$ and a mean ambient temperature of $7-8^{\circ} \mathrm{C}$. The soil type of experiment is Brown soil. Its physical and chemical properties are shown in table 1. 
Table 1 Physical and chemical properties of the soil

\begin{tabular}{c|c|c|c|c|c}
\hline soil type & $\mathrm{pH}$ & $\begin{array}{c}\text { available P ( } \\
\mathrm{mg} / \mathrm{kg})\end{array}$ & $\begin{array}{c}\text { available K } \\
\mathrm{mg} / \mathrm{kg})\end{array}$ & $\begin{array}{c}\text { available N ( } \\
\mathrm{mg} / \mathrm{kg})\end{array}$ & $\begin{array}{c}\text { organic matter } \\
(\mathrm{g} / \mathrm{kg})\end{array}$ \\
\hline Brown soil & 7.75 & 136.81 & 366.16 & 88.66 & 23.13 \\
\hline
\end{tabular}

Materials. The cultivar of Chinese cabbage in this study was "Liao Bai 12". Organic fertilizer was the mixture of sheep manure, clove leaf and agrocybe cylindracea residual compost, and its physical and chemical properties are as follows: $\mathrm{pH} 7.91, \mathrm{~N} 1.74 \%, \mathrm{P}_{2} \mathrm{O}_{5} 0.77 \%, \mathrm{~K}_{2} \mathrm{O} 1.20 \%$. Chemical fertilizer were urea $(\mathrm{N} 46 \%)$, potassium chloride $\left(\mathrm{K}_{2} \mathrm{O} 60 \%\right)$ and calcium superphosphate $\left(\mathrm{P}_{2} \mathrm{O}_{5} 12 \%\right)$.

Experimental design. Four treatments were set up, i.e. (1) CK, with no fertilizer application, (2) $\mathrm{CF}$, with chemical fertilizer, (3) CFOF, with chemical fertilizer and organic fertilizer, and (4) CFRF, with organic fertilizer replacing $30 \%$ of chemical fertilizer. 1.67 times of organic fertilizer are assumed to have the same effects to plants with chemical fertilizers. Detailed application information of fertilizer is shown in table 2. Chinese cabbage was planted on 31 August 2015 and harvested on 9 November in the same year.

Table 2 Detailed application information of fertilizer

\begin{tabular}{c|c|c|c|c}
\hline Treatments & $\begin{array}{c}\mathrm{N} \\
(\mathrm{kg} / \mathrm{ha})\end{array}$ & $\begin{array}{c}\mathrm{P}_{2} \mathrm{O}_{5} \\
(\mathrm{~kg} / \mathrm{ha})\end{array}$ & $\begin{array}{c}\mathrm{K}_{2} \mathrm{O} \\
(\mathrm{kg} / \mathrm{ha})\end{array}$ & $\begin{array}{c}\text { Organic fertilizer } \\
(\mathrm{kg} / \mathrm{ha})\end{array}$ \\
\hline $\mathrm{CK}$ & 0 & 0 & 0 & 0 \\
\hline $\mathrm{CF}$ & 180 & 90 & 135 & 0 \\
\hline $\mathrm{CFOF}$ & 180 & 90 & 135 & 3600 \\
\hline $\mathrm{CFRF}$ & 126 & 90 & 135 & 5190 \\
\hline
\end{tabular}

Sampling and Analytical Methods. After harvesting, the cabbage were collected, and weighed to obtain the fresh weight $(\mathrm{FW})$. After that, cabbage samples were firstly dried at $105^{\circ} \mathrm{C}$ for 30 minutes, then dried at $70^{\circ} \mathrm{C}$ until the weight is constant, and measured to obtain the dry weight (DW). The fresh plant samples were ground and used for measuring titratable acid, soluble sugar and nitrate content.

Data Analysis. Data calculation and statistical analysis were performed by using Microsoft Office Excel and SPSS 19.0.

\section{Results and Discussion}

The effects of different treatment on yield. According to the Fig.1, the yield of CF, CFOF and CFRF were significantly higher than $\mathrm{CK}(\mathrm{p}<0.05)$, and no significant differences were found in yield between $\mathrm{CF}, \mathrm{CFOF}$ and CFRF treatments. The yield of CFOF and CFRF treatments were higher than CF treatment $18 \%$ and $3 \%$, respectively. Thus both organic and chemical fertilizer have the abilities to improve the yield of Chinese cabbage, and the ability of combined application of organic and inorganic fertilizers were higher.

The effects of different treatment on moisture content. As shown in Fig.2, the highest and the lowest moisture content turned out in $\mathrm{CF}$ and CFRF treatments, respectively. And there were no significant differences in moisture content between $\mathrm{CK}, \mathrm{CF}, \mathrm{CFOF}$ and CFRF treatments. But compared with the moisture content in the treatment of $\mathrm{CF}$, the moisture content were lower in the treatments of CFOF and CFRF. 


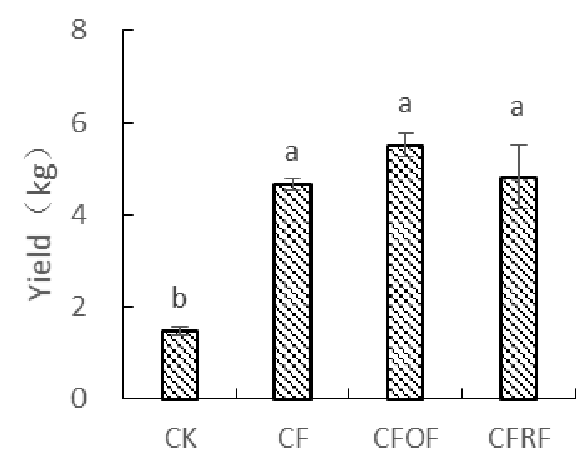

Fig.1 Yield of different treatment

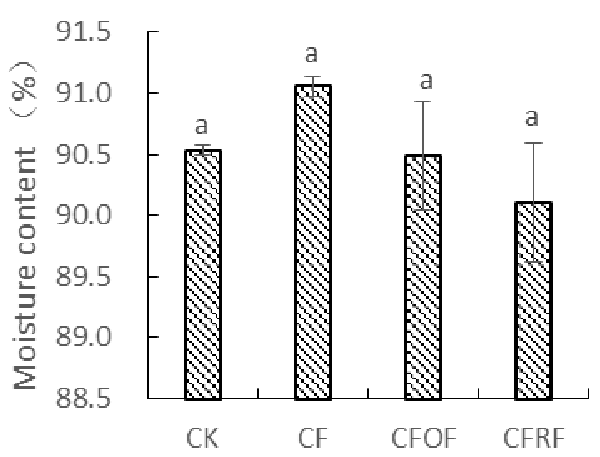

Fig.2 Moisture content of different treatment

The effects of different treatment on titratable acid content. As can be seen from the Fig.3, no significant differences were found in titratable acid content between $\mathrm{CK}, \mathrm{CF}, \mathrm{CFOF}$ and CFRF treatments. The lowest content was measured in CK treatment $(0.1024 \%)$ and the highest content was measured in CFRF treatment $(0.1266 \%)$. Compared to the CF treatment, combined application of organic and inorganic fertilizers can increase the titratable acid content.
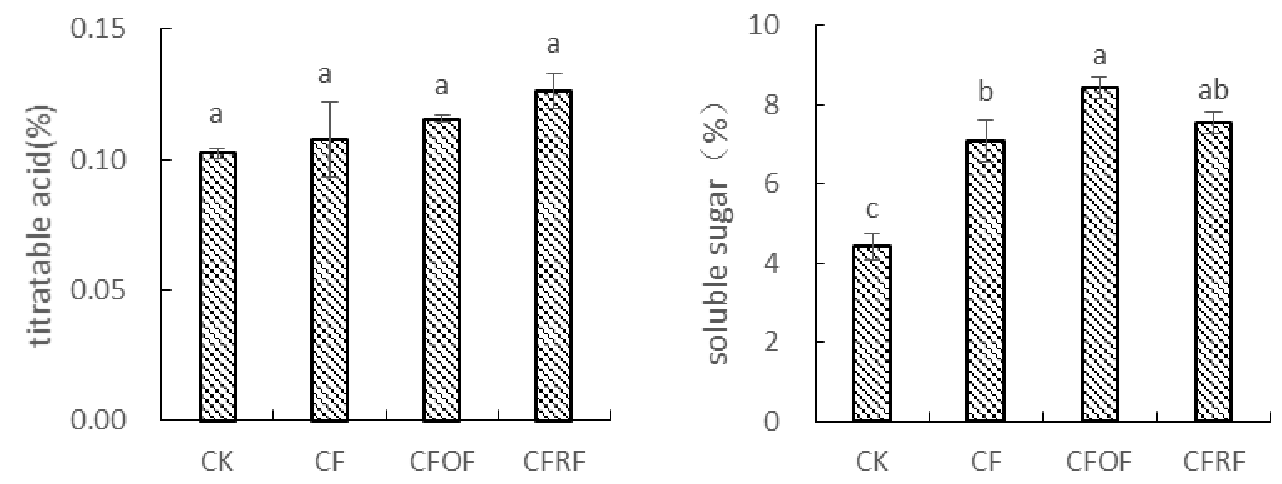

Fig.3 Titratable acid content of different treatment Fig.4 Soluble sugar content of different treatment

The effects of different treatment on soluble sugar content. We can see from Fig.4 that fertilizer improve the soluble sugar content significantly $(\mathrm{p}<0.05)$. The highest soluble sugar content occurred in the treatment of CFOF, which is significantly higher than CF treatment $(p<0.05)$. The difference in soluble sugar content between treatments of CFOF and CFRF was not significant, while soluble sugar content in CFOF treatment was higher than CFRF.

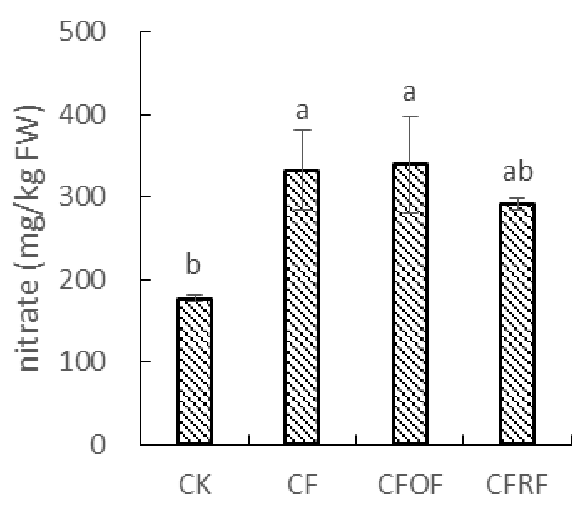

Fig.5 Nitrate content of different treatment

The effects of different treatment on nitrate content. Fertilizer application led to nitrate accumulations up to 290.71-332.86 mg/kg FW (Fig.5). The nitrate content of CF and CFOF treatments (332.86 and $339.19 \mathrm{mg} / \mathrm{kg} \mathrm{FW}$, respectively) was significantly higher than the CK treatment $(176.99 \mathrm{mg} / \mathrm{kg} \mathrm{FW})$. And no significant difference was found between nitrate content in CK and CFRF treatments. Compared with CF, CFRF can reduce the nitrate content of $14 \%$. 


\section{Conclusions}

The investigation revealed that, compared with chemical fertilizer treatment, the yield maintained stable in chemical fertilizer plus organic fertilizer treatment and organic fertilizer replacing $30 \%$ of chemical fertilizer treatment, and soluble sugar and titratable acid content increased and moisture content reduced. And nitrate content reduced in organic fertilizer replacing $30 \%$ of chemical fertilizer treatment, which is healthier to human. Therefore, Combined application of organic and inorganic fertilizers can meet the needs of Chinese cabbage yield and silmutaneously improve the quality. Thus, it is concluded that combined application of organic and inorganic fertilizers is suitable for Chinese cabbage production.

\section{Acknowledgements}

This work was financially supported by the Science and Technology Innovation Condition and Environmental Construction Project of Shenyang (1091179-1-00).We also wish to thank Dr. LiXia Zhao for help on improving the manuscript.

\section{References}

[1] G. Carbonell, R. Miralles de Imperial, M. Torrijos, M. Delgado, J.A. Rodriguez: Chemosphere. Vol. 85 (2011), p. 1614-1623

[2] G.Q. Huang, X.X. Wang, H.Y. Qian, T.L. Zhang, Q.G. Zhao: Ecological Environment. Vol. 13(2004,), p. 656-660, (in Chinese)

[3] X.L. Zhang, B.K. Zhou, L. Sun, Z.C. Gao: Chinese Journal of Soil Science. Vol. 39(2008), p.1221-1223, (in Chinese)

[4] X.Q. Feng, D.H. Yong: Gansu Science and Technology. Vol. 27(2011), p.143-147, (in Chinese)

[5] X.T. Ju, G.X. Xing, X.P. Chen, S.L. Zhang, L.J. Zhang, X.J. Liu, Z.L. Cui, B. Yin, P. Christie, Z. L. Zhu, F.S. Zhang: P Natl Acad Sci USA. Vol. 106(2009), p.3041-3046.

[6] A.G. Good, P.H. Beatty. Fertilizing nature: A tragedy of excess in the commons. PLoS Biol. 2011.9: e1001124.

[7] E. Aguilera, L. Lassaletta, A. Sanz-Cobena, J. Garnier, A. Vallejo: Agriculture, Ecosystems and Environment. Vol. 164 (2013), p. 32-52

[8] X. J. Liu, Y. Zhang, W.X. Han, A.H. Tang, J. L. Shen, Z.L. Cui, P. Vitousek, J. W. Erisman, K. Goulding, P. Christie, A. Fangmeier, F.S. Zhang: Enhanced nitrogen deposition over China. Nature. Vol. 494 (2013), p. 459-462. 